\title{
XLI. Outlines of a philosophical inquiry into the nature and properties of the blood; being the substance of three lectures on that subject delivered at the Gresham Institution during Michaelmas Term 1826
}

\section{John Spurgin M.D.}

To cite this article: John Spurgin M.D. (1827) XLI. Outlines of a philosophical inquiry into the nature and properties of the blood; being the substance of three lectures on that subject delivered at the Gresham Institution during Michaelmas Term 1826, Philosophical Magazine Series 2, 1:3, 199-207, DOI: 10.1080/14786442708674273

To link to this article: http://dx.doi.org/10.1080/14786442708674273

曲 Published online: 10 Jul 2009.

Submit your article to this journal ¿

III Article views: 3

View related articles $\sqsubset$ 
cing a piece of zinc or tin. This in the case of steam boats, particularly when salt water is used, may be of the greatest advantage, and prevent the danger of explosion, which generally arises from the wear of one part of the boiler.

Another application of importance which may be made, is the prevention of the wear of the paddles or wheels, which are rapidly dissolved by salt water.

But I will conclude. Whenever a principle or discovery involves or unfolds a law of nature, its applications are almost inexhaustible; and however abstracted it may appear, it is sooner or later employed for common purposes of the arts and the common uses of life.

XLI. Outlines of a Philosophical Inquiry into the Nature and Properties of the Blood; being the Substance of three Lectures on that Subject delivered at the Gresham Institution during Michaelmas Term 1826. By John Spungin, M.D. Fellow of the Royal College of Physicians of London, and of the Cambridge Philosophical Society *

THE plan pursued in these Lectures, in regard to the mode and style of their composition, being intended rather for the general class of intelligent hearers, than for the medical profession exclusively, it may readily be conceived that a departure from what might be termed the usual method of treating a physiological subject like that of the blood, was almost unavoidable, at the same time that it might be deemed in some degree justifiable. The philosophical and abstract reasoning upon the nature and properties of this fluid, directed and limited as it is, by the facts, the observations, and the experiments which are adduced concerning it, will not, it is hoped, be thought unworthy of attention, or destitute of interest and utility.

To confine the Lectures to a bare enumeration of facts, to the exclusion of all reasoning, was not so much the object in their composition, as to draw conclusions from them, that might lead to further inquiry on the same subject; at the same time that they interested the hearers; and as the Lectures were not drawn up with any view to publication in their present shape, they may perhaps be entitled to indulgence for the novelty of the method adopted, in the investigation of this important part of the Animal Economy.

To enter upon a course of investigation into the economy of the animal kingdom, or in other words, to bring the

* Communicated by the Author. 
human faculties into exercise with the view to discover the uses and ends of all the parts which compose this kingdom; more qualifications are required than might at first sight be imagined : for not only is it necessary to possess a thorough knowledge of the anatomy of the body, but likewise to be conversant. with several other highly iniportant branches of science, both mathematical and physical, and to be initiated moreover into that sort of abstract or philosophical reasoning, which enables us to discern the difference between a cause and its effect; or to perceive the relationship that subsists between a substance, and the forces and powers which it may be the medium of manifesting.

The investigation then of the animal economy requiring so many aids, we must not be surprised at the slow progress of our knowledge concerning it, nor ridicule the various strange hypotheses and fancies of our ancestors; still less ought we to contend with any one of our own day for or against an. opinion, as if it were an empire; because if we are guided by experience, and the clear deductions of reason, the truth will in all probability be eventually attained, to the dispersion of error. But as I am precluded from entering upon such an investigation, or upon a consideration of the animal economy, to any great extent, and can only take up the subject in a very general and cursory manner, $I$ have ventured to draw your attention to the most important part of this economy, viz., the blood: because the animal system regards the blood as its common fountain and source; and in a philosophical point of view, it may be said to be a general principle pervading and entering into every part and portion of the body.

I should be extremely unwilling to offer any thing to your consideration, which might not prove either interesting or useful to you in some degree; but if the rule which insists on an enumeration of facts, to the exclusion of all reasoning, and which is too generally acted upon, be taken as the measure of this interest or utility; the prefatory remarks with which I have set out, and which have been drawn up in opposition to the rule just alluded-to, will, I fear, prove insipid to some, and useless to others: but as in the pursuit of my plan there is an abundance of facts to bring forward, and as some indulgence is claimed in an Introductory Lecture, I trust you will find the general rule complied with in the sequel, whilst I avail myself of your indulgence at the outset.

If therefore we in the first place take an abstract or more philosophical view of this most extraordinary fluid, the blood; we may discern in it, as in a type, all the individual parts' of the animal economy; seeing that neither the solids nor the remaining fluids of the body are derived to it, from any other 
source than from the blood; we may also be enabled to see in what manner, and under what sense, it may be regarded as the life of the body; inasmuch as our experience proves to us, that the state and condition of animal life depends upon the nature, constitution, determination, continuity and quantity of the blood; and that under the same view, its vessels, or the arteries and veins, are neither more nor less than its determinations, composing in fact for the most part the entire body. Moreover, when the proofs to be derived from the best chemical authorities are adduced, of the variety of elements, whether ultimate or proximate, that enter into the composition of the blood, it will be seen that this fluid is in fact a complex of many things existing in the world, and as it were, a seminary and storehouse of whatsoever exists in the body; for it contains, as will be shown in the next lecture, salts of various kinds, both fixed and volatile, and the gaseous elements, -as oxygen, hydrogen, and azote; in short, numerous products from the three kingdoms of nature, - the animal, vegetable, and mineral; and imbibes also those things which the atmosphere conveys in its bosom or holds in solution; for by means of the lungs or respiratory apparatus, it exposes itself to the air, to be enriched with its treasures.

Now as the blood contains in itself, in this compendious manner, so many of the productions of the whole world, and of its several kingdoms; may it not be allowable to infer that these were all created for this end, -namely, to administer to its composition and continual renewal? For it may be rationally argued, that if all things were created for the sake of man, and to afford him the means of subsistence and thence of life; then all things were created for the sake of the blood, which is the parent and nourisher of every part of the body: for nothing exists in the body wohich did not first exist in the blood.

So true is this, that if the texture of any muscle or gland, of which the viscera are for the most part compounded, be divided into its minutest parts, it will be found to consist chiefly of vessels containing blood, and of fibres or nerves containing, or conducting, without doubt, a corresponding and more eminent fluid or blood. And even those parts which do not appear to consist of such vessels, - as the bony, cartilaginous and tendinous structures, --will nevertheless be found in their soft and infant state, or during infancy, to be similarly composed, as experience can prove. The blood then is not only a treasury and storehouse enriched with all the various productions of nature, and thence enabled to bestow on the body, as its offspring, whatever it requires for necessity and use;
New Series. Vol. 1. No. 3. Mar. 1827.
$2 \mathrm{D}$
but 
but is also, as it were, its all in all; and in it are contained the means which enable man to live in a corporeal form in this outward world, in the manner we behold.

But in order to our completing the circle of investigation upon the blood, and thence obtaining a true knowledge and correct doctrine respecting it : a knowledge of those things which enter into its composition and constitution is indispensable, as also an examination of all the viscera, members, organs and tunics, which are vivified by its passage through them; for whilst the nature of these is unknown, and their modes of existence and action, the nature of the blood remains unknown also. It is impossible for us to enjoy any clear ideas upon any subject, if certain parts of that subject remain unknown or obscure to us : a full and complete idea of any subject, can only be attained from a knowledge of every particular which the subject involves; and conseqnently, our knowledge of the nature of the blood can only keep pace with that of the things which enter into its composition, and of those in which it is contained, as the blood-vessels and organs composing the body.

From these remarks it may sufficiently appear how many sciences are included in that of the blood:-anatomy, medicine, chemistry, and natural philosophy, with their respective sub-divisions are evidently so; and not only these, but even psychology is requisite, for the mind or mental powers suffer according to the state of the blood; and the blood, again, is under the influence of the passions of the mind:-in a word, every science that treats of the substances of the world and the powers of nature ought to be consulted. Such considerations as these enable us, moreover, to discern the ground and reason of man's not being called into existence till all the kingdoms of nature were finished. The world and nature seem to have concentrated themselves in him; that in him, as in a microcosm, the whole universe from first to last might be contemplated.

It is expedient on all occasions to keep close to experience, and also to follow the order of nature; according to which, a distinct idea is always preceded by an obscure one, and a par-. ticular idea by a general one : for we never perceive any thing distinctly, unless we dednce it from, or refer it to, some common source, and universal principle. For such is the condition of our mind and senses in their advancement to perfection and subsequent actions. We are born densely ignorant and insensible; it is only by degrees that the organs are opened, as it were: the images and notions which we first conceive are extremely obscure, insomuch that, so to speak, the whole universe 
Inquiry into the Nature and Properties of the Blood. 203

universe is presented to the eyes as a single indistinct thing, a shapeless chaos : yet all things in process of time become more distinct, and at length make their way to the rational faculty of the mind; - thus are we a long time in becoming ram tional.

Whether we have discovered the truth or not, respecting any subject, is easily ascertained ; for all experience will then spontaneously bear testimony in its favour, so likewise will every rule of true philosophy : for when truth is at hand, nothing whatever refuses it its suffrage; hence it immediately manifests itself, and commands belief, or, as is commonly expressed, presents itself naked.

Nothing can introduce us to the causes of things, or to truth, but experience alone: for when the mind or contemplative faculty is left to expatiate without restraint, or without experience for its guide, how easily does it fall into error, and go stumbling on from one absurdity to another; and if it then looks to experience for confirmation and patronage, the attempt will be wholly useless" and vain. To consult experience after assuming our principles is an erroneous mode of proceeding: we should on the contrary consult experience first, and deduce our principles from it; when we are led away by reasoning alone, we are not unlike those who, with their eyes blindfolded, as is sometimes practised in childish sport, believe themselves to be walking in a straight direction, but who on the removal of the bandage find that they have wandered greatly from the path, and that if they had continued their blind progress they would have arrived by a circular course, at a place the very opposite to that of their destination.

But it may be inquired whether we have at the present day a sufficient store of experience or of facts to enable us to discover Nature's secrets so successfully as the above considerations would lead us to expect, without its being necessary to suffer our minds to wander into the wild field of conjecture unrestrained by experience. It cannot be denied that our experience or our knowledge of any one individual thing, let it even be enriched and increased by the accumulated experience of ages, can never suffice to complete the investigation of the subject to which it relates, to its very and inmost causes. But if all that is known, or all our general experience in anatomy, medicine, chemistry, physics, and the other natural sciences, be called to our aid in the exploration and investigation of any i idividual thing, - as in this instance in the investigation of the blood, we may affirm that we are at this day sufficiently provided for the purpose.

When we confine our experimental research to a single ob$2 \mathrm{D} 2$ 
ject, as to the blood, or to a muscle, or a gland; this research can never be so complete as to exhaust and to display all the hidden qualities of that object. Let us take the blood for an example: The experiments which have been made upon it only inform us that its colour is of different degrees of redness; that it is heavier than water; that it sinks to the bottom of the serum; that it is of a gentle and almost uniform warmth in the body; and that it contains salts both fixed and volatile, of several kinds, besides other things, such as albumen, and fibrin, which are termed animal matter; and variable proportions of water. But these experiments alone do not inform us whence its redness, its gravity, and its heat, derive their origin; nor in what way the products to be obtained from it by distillation, or by means of chemical analysis, are preserved therein in that peculiar combination and form that renders the blood such an homogeneous and simple fluid as it appears to be in its natural and fluid state, These latter points must be regarded as so many accidents and essentials, the knowledge of which is only to be sought for and obtained in common or more general experience, or in our experience as taken in its whole compass and course. For we do not hesitate to assert, nor are we afraid to maintain, that whenever a subject is defined and determined by occult qualities, it remains as obscure and unintelligible as if no definition or description had ever been given; in like manner as we stop at the very threshold of the science of angiology, or of the circulation of the blood, if we do not learn the whole anatomy of the body and of ail its viscera; that is, unless we closely pursue the blood into all the recesses into which it flows.

The case is similar in all other instances, whether in anatomy, or physics. Thus, if we would investigate the causes of the action of a muscle or moving fibre, our labour will be in vain, unless, in addition to our more confined experience or knowledge of the muscle or fibre itself, as to its particular form or situation, we are at the same time acquainted with many of the particulars relating to the rest in the body, and likewise with those relating to the blood, its arteries, and heart, to the nerves, ganglia of nerves, medulla oblongata and medulla spinalis, to the cerebellum, the cerebrum, and to many of the members, organs, and tunics endowed with the faculty of muscular motion: and not only so, but we ought also to know the chief particulars relating to those parts of physics and mechanics, which treat of forces, elasticity, motion, and several other subjects.

Thus it may be seen, how, from a knowledge or experience of the particulars involved in any one subject, our notions and 
ideas of that subject are but very obscure and indistinct; but how that in process of time and by diligent study, these ideas may be rendered more distinct and clear, by means of the general experience we may have at length acquired: for as we observed above, it takes a long time for man to become rational; or in other words, for the rational faculty of man to become stored with those truths which are indispensable to his becoming a truly rational or intelligent being.

We cannot help bringing to your notice the connexion, communion, and mutual respect existing between all things of the world and nature; - for does not one science meet and enlarge our apprehension of another, and every new acquisition afford an explanation to what preceded? By many and rarious facts judiciously associated and mutually compared, our ideas are illustrated and our reason illuminated ; for it is only by degrees that the mind disperses the shadows and clouds of ignorance and prejudice, and emerges thence into light. Still, however, there is a danger of our relying upon omthorough knowledge or experience of some single subject, as a means of our extending our reasoning to other things with which it may have only a remote connexion. Examples of this are too abundant in our own day: for how many are there who are well skilled in one particular science, and who would investigate or measure every other, by it alone. Thus the chemist may look for nothing but chemical affinities and decompositions in the three kingdoms of nature; the mathematician for nothing but gravitating tendency, polarity, centripetal and centrifugal forces; the anatomist, for nothing but structure and form; the painter, for nothing but colour, light and shade; the musician, for nothing but harmony and sound; and the physician, for nothing but irritability, and numerous other technicalities. Drawing general conclusions from such confined sources, how dexterously does such limited experience favour the mind in all its reveries, and how obstinately does it withstand the objections advanced by the truly rational antagonist? The reason of this is, because no fact can exist which may not be placed in some part or other of different series of ratiocinations; just as one syllable, word, or phrase, may enter into and form a part of innumerable sentences and discourses; one idea of innumerable series of thoughts, and one colour of innumerable pictures. One thing may always be inserted on another, as branches are by the gardener; and thus a false inference may be grafied on a certain fact, as a wild fruit-tree on the legitimate growth of the orchard.

To avoid, therefore, being made the dupes of appearances, we should never yield our assent to any theory, wilhout its having the concurrence of common or general experience; or 
unless all the facts which can be brought to bear upon it unite their suffrages in its favour; that is, unless the final conclusions are connected with and confirmed by the mediate links, throughout their whole progression. To me it appears that there is no other possible way for an edifice to be constructed, or for a system of philosophy to be formed, which posterity shall acknowledge, on the superadded testimony of thousands of new experimental discoveries, to rest on a solid foundation, and it shall no longer be necessary for every age to be perpetually erecting new structures on the ruins of the former.

If a time shall ever arrive when the human mind will be enabled to deduce an entire series of conclusions from the facts and general experience with which it can be furnished, so as to build up a more harmonious and consistent philosophy than we at present enjoy; the facts themselves and our general experience must be of that definite and indisputable kind that will impress on our minds a conviction of their immutability. To such a state of things are we undoubtedly advancing; but it is impossible to say how remote we are from this state at present. Every science requires of its cultivators a rejection of hypothesis and an attainment of certainty, to such a degree almost as to admit of calculation: in no instance is this more apparent than in chemistry. Consequently we may with justice aver, that we are advancing to a period when the human mind will be enabled to philosophize more consistently and harmoniously than heretofore; more especially as we have good reasons for supposing that the human mind, regarded in itself and as to the complex of its astonishing faculties, is as perfect in one age as in another; is as capable of instruction at the infancy of a state as at its maturity: the only requisites being, good materials for its development, and well-established facts as things upon which it can be exercised;-it being in this respect exactly similar to the human body, which is as perfect at this day as it was ages ago; as capable of imbibing nonrishment in the peasant as in the prince,- the only requisites being wholesome food for its growth and repair, and active pursuits to preserve it in vigour. An analogy of this kind may also be seen to exist, between the gradual advance of mankind from barbarism to civilization, and the gradual progress of the mind from ignorance to intelligence : for whilst history in recording the one, interests us with the extraordinary feats of mighty heroes and conquerors; so do the volumes of literature in containing the other, astonish us with the vast manifestations of mental power exhitited by profound reasoners and skilful experimenters.

At no period of the world was the human mind so quali- 
fied for bringing its various faculties into full exercise, and to a more complete exhibition of its inherent powers, than at the. present :--for never was it so free to act its part in thinking, judging, and deciding upon, any matter: never did it enjoy such a vast accumulated store of experience, for its basis and direction; never did it exhibit such a thirst after and such a relish for knowledge; never did it betray such a disposition to scrutinize the theories, doctrines and traditions which have so long held her in bondage, as at the present day. And surely if it be disposed for what is good, as well as for what is true, its gratitude to the country and age which is now yielding to its empire, will increase with the auspicious extension of its dominion. In every department of science it must be admitted that such sentiments as the above are now tacitly acknowledged; and if they prevail to any benefit, we think we shall not err in saying, that this benefit will in no instance be more apparent than in that of medicine. This science is classed, and rightly too, among the liberal sciences; and we hope it will not only continue to hold so respectable a rank among them, but whilst conducing to the common good of mankind, exhibit among its cultivators a good-will and fellow-feeling which will prompt them to regard each other's sentiments, upon every subject, with mutual candour and forbearance; - for where the good of society is the object, there the heart, the head, and the hands, will conspire to promote it.

It being then one of the purposes of this Institution to deliver lectures on some subject of medical science to any individuals who may wish to acquire some knowledge respecting it, it is quite impossible to convey such knowledge in any other than a very general way indeed; wherefore I have thought it expedient, from the circumstance of my merely occupying Dr. Stanger's place during his absence from town, to enter upon a subject, which, though the most general of all, and thence perhaps the least understood, yet involves so many particulars of interest as well as of general experience, that the subject may be regarded as worthy of your attention and consideration.

The subject I allude to, is the blood. To a thorough knowledge of which so many requisites are indispensable, that we intend only to bring forward common facts, or general experience, in framing our doctrine concerning it.

But as the time will not allow of my bringing forward the results of the experiments to which this fluid has been subjected, I must beg to defer this material part of my subject to the next lecture. And at our third meeting I hope to have it in my power to proceed to consider two of the most interesting and remarkable properties of the blood,-viz. its Fuurdity and VITALITY.

[To be continued.]

XIII. On 